Postharvest Biology and Technology 121 (2016) 143-150

Contents lists available at ScienceDirect

Postharvest Biology and Technology

journal homepage: www.elsevier.com/locate/postharvbio

A mechanistic model to describe the effects of time, temperature and exogenous ethylene levels on softening of kiwifruit

Maarten L.A.T.M. Hertog ${ }^{\mathrm{a}, 1}$, Peter B. Jeffery ${ }^{\mathrm{a}}$, Sunny George Gwanpua ${ }^{\mathrm{a}, *}$, Nagin Lallu ${ }^{\mathrm{b}}$,

Andrew East ${ }^{\mathrm{a}}$

a Centre for Postharvest and Refrigeration Research, Massey University, Palmerston North, New Zealand

b Plant and Food Research, Private Bag 92 169, Auckland, New Zealand

1

\title{
A mechanistic model to describe the effects of time, temperature and exogenous ethylene levels on softening of kiwifruit
}

Maarten L.A.T.M. Hertog ${ }^{1, \#}$, Peter B. Jeffery ${ }^{1}$, Sunny George Gwanpua ${ }^{1,{ }^{*}}$, Nagin Lallu $^{2}$, Andrew East ${ }^{1}$

${ }^{1}$ Centre for Postharvest and Refrigeration Research, Massey University, Palmerston North, New Zealand

${ }^{2}$ Plant and Food Research, Private Bag 92 169, Auckland, New Zealand

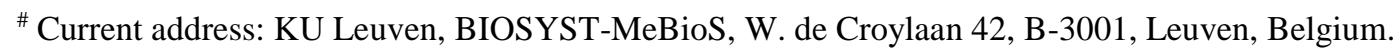

* Corresponding author: Tel.: +64 6951 9253. E-mail: s.gwanpua@ massey.ac.nz (S.G. Gwanpua).

\section{Abstract}

Early harvested kiwifruit (Actinidia deliciosa (A Chev) Liang et Ferguson cv 'Hayward'), from 14 growers and two seasons were stored under a wide range of storage temperatures $\left(0-10{ }^{\circ} \mathrm{C}\right)$ and exogenous ethylene levels $\left(0-200 \mu \mathrm{L} \cdot \mathrm{L}^{-1}\right)$ followed by an ethylene free shelf life period at 0-20 ${ }^{\circ} \mathrm{C}$. Firmness levels were monitored using a non-destructive compression technique. A mechanistic model, based on a simplified representation of the physiology underlying fruit softening, explained $97 \%$ of the observed variation. 
17 The kinetic model parameters appeared to be generic for the 14 grower lines studied.

18 Differences between the grower lines could be explained based on differences in the initial

19 firmness levels and the initial amounts of active enzyme system present.

20 The model was validated with independent experimental data on the softening of 70 batches of

21 main harvest kiwifruit stored at $0{ }^{\circ} \mathrm{C}$, with more than $99 \%$ of the variation explained for each

22 of the 70 grower lines. A further validation was done using literature data on shipping of

23 "Kiwistart" fruit under dynamic temperature and ethylene conditions.

24 Keywords: ethylene, kiwifruit softening, modelling, ripening, temperature

\section{1. Introduction}

The New Zealand kiwifruit industry provides ready-to-eat kiwifruit (Actinidia deliciosa (A

Chev) Liang et Ferguson cv 'Hayward') to overseas markets by harvesting early season kiwifruit, and ripening this fruit during shipping by applying ethylene at elevated temperatures (Lallu et al., 1989). A key criterion for consumers in their acceptance of this so-called "Kiwistart" fruit, is firmness, with an "eating window" of between 4-8 N (MacRae et al., 1990). Following long term storage of the "main harvest" fruit, kiwifruit lines intended for export by New Zealand kiwifruit industry must have a 'soft fractile' greater than $9.81 \mathrm{~N}$. The soft fractile is defined as the $3^{\text {rd }}$ percentile in a sample of 300 fruit, i.e. the $9^{\text {th }}$ softest fruit of a sample of 300 must be greater than $9.81 \mathrm{~N}$ (Jabbar, 2014).

The rate of kiwifruit softening is affected by time, temperature, exogenous ethylene levels and maturity of the fruit (Burdon et al., 2014; Jabbar and East, 2016; Pranamornkith et al., 2012;

37 Ritenour et al., 1999). Although the climacteric rise in ethylene production in kiwifruit only occurs after the fruit have undergone substantial softening, small amounts of exogenous ethylene can rapidly accelerate softening even at low temperatures. Generally, kiwifruit softening follows a triphasic curve with different enzymes responsible during the subsequent 
41 softening phases (Bonghi et al., 1996; Redgwell et al., 1992; Schröder and Atkinson, 2006).

42 While considerable amount of research has been done to understand the mechanism of kiwifruit softening, most attempts to model softening of kiwifruit have been based on purely empirical models (Benge et al., 2000b; Jabbar et al., 2014). Although these models can be used to describe biological systems, their parameters have no obvious biological meaning, and as a result, their generic and predictive value is generally limited. Mechanistic, or kinetic-based, models have been used to describe softening in avocado (Hertog et al., 2003; Ochoa-Ascencio et al., 2009), apples (Gwanpua et al., 2013, 2012; Hertog et al., 2001), peaches (Tijskens et al., 1998), and tomatoes (Van Dijk et al., 2006). Hertog et al. (2004b) used a Michaelis-Menten type kinetics to model the impact of the rate of respiration on the rate of kiwifruit softening. While this approach focussed on a wide matrix of gas conditions at different temperatures the actual softening pattern was not monitored as they only measured the overall change in firmness over a fixed period of time. So far, no attempt has been made to extensively model the impact of ethylene on kiwifruit softening.

Our aim was to develop a robust mechanistic model, based on simplified physiological concepts, that would enhance the interpretation of kiwifruit softening behaviour under a wide range of storage and shelf-life situations combining the effects of time, temperature and exogenous ethylene. Such a model will enable the New Zealand kiwifruit industry to define storage requirements to reliably bring ready-to-eat "Kiwistart" fruit to the market.

\section{Material and methods}

\section{1 "Kiwistart" storage trials}

The storage trials with "Kiwistart" fruit were conducted at Massey University, Palmerstone North, New Zealand. The experimental work characterised in detail the effect of different ethylene applications at different temperatures on the softening of batches of "Kiwistart" fruit from two seasons (2000 and 2001) during both storage and subsequent shelflife. This enabled 
66 a robust calibration of the model. The storage period of four weeks reflected the time required to ship "Kiwistart" fruit from New Zealand to Europe.

\subsubsection{Fruit}

Export quality “Kiwistart” fruit (Actinidia deliciosa (A Chev) Liang et Ferguson cv Hayward)

were obtained from growers from Te Puke, New Zealand. In 2000 fruit from four growers were harvested on April 17 $7^{\text {th }}$ In 2001 fruit obtained from ten growers were harvested on April $25^{\text {th }}$ $-26^{\text {th }}$. After harvest fruit were graded, packed and couriered overnight to Massey University.

On arrival, fruit were randomised, individually labelled, and initial fruit measurements were taken. Samples of 30 fruit each were assigned to each of the storage treatments for nondestructive firmness monitoring.

\subsubsection{Fruit measurements}

Throughout the experiments fruit firmness was measured non-destructively by recording the maximum compression force required to compress tissue for $1.5 \mathrm{~mm}$ using the standard penetrometer cylinder probe ( $7.9 \mathrm{~mm}$ diameter) used for destructive firmness measurements in the kiwifruit industry. The probe was mounted on a TA-XT2 texture analyser (Stable Micro Systems Ltd.). The compression test was run using a pre-test speed of $2 \mathrm{~mm} \mathrm{~s}^{-1}$, a test speed of

$821 \mathrm{~mm} \mathrm{~s}^{-1}$, and a trigger force of $0.0015 \mathrm{~N}$. A compression test begins when the probe travels to the fruit's surface at pre-test speed and detects an initial resistance of a given value (the trigger force) as it begins to make contact with the fruit after which it continues to compress the fruit at the test speed. All fruit were tested at weekly intervals at their respective storage or shelf life temperatures. Fruit were measured until they reached a firmness of about 5 N. After each measurement, the measured spots were marked with a felt-tip pen to prevent subsequent measurements from being taken at the same spot. 
Only during the 2000 season destructive firmness measurements were taken at certain stages to compare to the non-destructive measurements. At the start of the experiment, and at the end of the ethylene treatment destructive firmness readings were taken on a separate batch of 30 fruit. At the end of shelf life, firmness of all remaining fruit was destructively measured as well. Destructive firmness readings were taken using the standard penetrometer cylinder probe (7.9 mm diameter) mounted on a TA-XT2 texture analyser (Stable Micro Systems Ltd.). A piece of skin about $2 \mathrm{~mm}$ thick was removed using a cutting device with a fixed blade. The test was run using a pre-test and a test speed of both $10 \mathrm{~mm} \mathrm{~s}^{-1}$, a trigger force of $0.0015 \mathrm{~N}$, and allowing the probe to travel $9 \mathrm{~mm}$ deep into the tissue, measuring the maximum force encountered.

\subsubsection{Storage conditions}

A flow-through system using $75 \mathrm{~L}$ barrels located in temperature-controlled rooms was used to generate the intended conditions and to prevent contamination from other potential ethylene sources. Before entering the barrels, the gas stream was humidified by bubbling through jars with water. Depending on temperature, flow rates were controlled at $0.6-1.9 \mathrm{~L} \cdot \mathrm{min}^{-1}$ to prevent accumulation of $\mathrm{CO}_{2}$ and depletion of $\mathrm{O}_{2}$.

During the 2000 season, fruit from each of the four growers were stored for 4 weeks at one of 16 temperature-ethylene combinations generated by continuously applying ethylene levels of $0,0.1,10$ or $200 \mu \mathrm{L} \mathrm{L}^{-1}$ at temperatures of $0,2,5$ or $10{ }^{\circ} \mathrm{C}$. After these ethylene treatments, fruit were stored for up to 6 weeks shelf life at $0,5,10$ or $20^{\circ} \mathrm{C}$ under ethylene free air. The factor grower was used as a blocking factor assigning each of the 64 possible storage temperature $\mathrm{x}$ ethylene level $\mathrm{x}$ grower combinations to one of the 4 shelf life temperatures in such a way that the 4 growers together covered all possible storage temperaturexethylene level $\times$ shelf life temperature combinations, making sure that these main factors were equally represented per grower (Table 1). 
114 During the 2001 season, fruit from each of the ten growers were stored for 5 weeks at one of 6

115 temperature-ethylene combinations generated by continuously applying ethylene levels of 0,2

116 or $100 \mu \mathrm{L} \mathrm{L}^{-1}$ at temperatures of 0 or $2{ }^{\circ} \mathrm{C}$. After these ethylene treatments, fruit were stored

117 for up to 8 weeks shelf life at 0,10 or $20{ }^{\circ} \mathrm{C}$ under ethylene free air in such a way that all

118 possible storage temperaturexethylene level $\times$ shelf life temperature combinations were

119 covered. Similar to the 2000 season the possible storage combinations were blocked over three

120 groups of growers. (Table 1).

121 The term shelf life is used to indicate the storage period under ethylene free air although the

122 temperatures applied are not necessarily typical 'shelf life' temperatures.

123 In both years a flow-through system was used to generate the different levels of ethylene by mixing ethylene standard gases with air. Ethylene concentrations were regularly checked using gas chromatography (Varian 3400, USA, fitted with flame ionisation detector and a mesh alumina column with nitrogen as carrier gas and a Hewlett Packard Integrator, model 3395A).

\subsection{Main harvest validation trial}

Data for an independent validation with main harvest kiwifruit was obtained from trials done at Plant \& Food Research, Mt Albert, New Zealand. Data was provided from a soft fruit prediction trial dated from 1998. The experimental work characterised in detail the variation observed between softening rates of different commercial grower lines at $0{ }^{\circ} \mathrm{C}$. This enabled a robust validation of the developed model using independent data.

\subsubsection{Fruit}

134 For this trial, 70 orchards aligned with five packhouses in the Bay of Plenty were selected.

135 Fruit from each orchard were harvested after reaching full commercial maturity, graded and 136 packed at one of the five packhouses. Five modular bulk packs of average count size for each 
137 orchard were collected after packing and transferred to Mt. Albert, Auckland, and left over 138 night before cool storage at $0{ }^{\circ} \mathrm{C}$ for 24 weeks.

140 Fruit firmness was measured destructively once every 4 weeks on a batch of 20 fruit using a

141 handheld Effegi penetrometer equipped with a $7.9 \mathrm{~mm}$ cylindrical head.

142 In addition, some fruit attributes thought to be related to maturity at harvest were measured on 143 a 20 fruit sample for a subset of 27 of the 70 orchards. These at-harvest parameters were the 144 soluble solids content (SSC), firmness, relative water content (RWC), electrolyte leakage rate $145(E L R)$, mineral composition and reducing sugar content of the juice. SSC was determined using 146 a hand-held Atago refractometer, while the $R W C$ was determined from fresh weight $(F W)$, 147 hydrated fresh weight (Turgid), and dry weight $(D W)$ measurements on $1 \mathrm{~mm}$ thick discs of 148 pericarp tissue. The discs were weighed after blotting to remove any free moisture and then 149 placed between filter papers moistened with distilled water in a petri dish to rehydrate. The 150 disks were reweighed at intervals until the increased or turgid weight was constant (Turgid), 151 after which the $D W$ of the discs was determined by drying the discs at $60^{\circ} \mathrm{C}$ for 12 to 16 hours. $152 R W C$ was calculated as:

$$
R W C(\%)=(F W-D W) \times \frac{100}{(\text { Turgid }-D W)}
$$

$154 E L$ was determined using a core sample next to and $90^{\circ}$ to that used for $R W C$ determination. Two $2 \mathrm{~mm}$ thick discs of outer pericarp tissue were taken from each fruit, and placed into 20 $156 \mathrm{~mL}$ of a $0.4 \mathrm{M}$ mannitol solution for 5 hours at $25^{\circ} \mathrm{C}$. The electrical conductivity of the solution 157 was measured initially and again at hourly intervals. The tubes containing the discs were then 158 placed at $-20{ }^{\circ} \mathrm{C}$ overnight, thawed, and returned to the water bath at $25{ }^{\circ} \mathrm{C}$ before electrical 
159 conductivity was again measured to determine the total electrolyte leakage rate. ELR was

160 calculated as a percentage of total leakage per hour.

161 Juice from a 4 fruit sample for each of the 27 subsets of the orchards was collected into a

162 beaker, using a garlic press. Two aliquots of approximately $2 \mathrm{~mL}$ were then pipetted into

163 Eppendorf tubes, and kept frozen at $-20^{\circ} \mathrm{C}$ until analysis by a commercial analytical company

164 (R J Hill Laboratories Ltd., Hamilton). The juice was analysed for nitrogen (N), potassium (K),

165 calcium $(\mathrm{Ca})$, magnesium $(\mathrm{Mg})$ and reducing sugar (fructose + glucose) content.

\section{3. Model development}

\subsection{Model formulation}

168 The purpose was to develop a model that would help interpret the softening behaviour of 169 kiwifruit in a wide range of storage and shelf life conditions and could find practical application 170 in optimising the logistic chain for kiwifruit. This required a model that was closely linked to

171 the actual product physiology, but sufficiently simple to enable robust calibration. Based on

172 the general softening curves available in the literature, a simplified mechanism was proposed

173 resulting in the following model formulation.

174 Firmness $(F)$ is believed to be related to the amount of intact structural cell wall compounds $175(C W)$. The breakdown of this $C W$ was assumed to be actioned by a single enzyme system ( 176 Enz ) resulting in:

177 $E n z+C W \stackrel{k_{p}}{\longrightarrow} E n z$

178 with $k_{p}\left(\mathrm{~d}^{-1}\right)$ being the rate constant for the enzymatic breakdown of $C W$. To reflect the 179 autocatalytic character of the process of fruit ripening, the enzyme responsible for fruit 180 softening is assumed to be formed from an inactive precursor $\left(E n z_{\text {pre }}\right)$ via an autocatalytic process - i.e., the activated enzyme further activates its own inactive precursor: 
183 with $k_{a}\left(\mathrm{~d}^{-1}\right)$ being the rate constant for the activation of the enzyme responsible for softening.

184 Exogenous ethylene $\left(\mathrm{C}_{2} \mathrm{H}_{4}\right.$ in $\left.\mu \mathrm{L} \mathrm{L}^{-1}\right)$ was also assumed to catalyse this enzyme activation, 185 resulting in:

186

$$
E n z_{\text {pre }}+\mathrm{C}_{2} \mathrm{H}_{4} \stackrel{k_{e}}{\longrightarrow} \mathrm{Enz}+\mathrm{C}_{2} \mathrm{H}_{4}
$$

187 with $k_{e}\left(\mathrm{~d}^{-1}\right)$ being the rate constant for the activation of the enzyme by ethylene. This single reaction comprises the complex action of ethylene of which the biochemical details are still largely unknown. This reaction is not suggesting that $\mathrm{C}_{2} \mathrm{H}_{4}$ itself is activating the precursor but

190 it is merely stating that the activation of the precursor is somehow regulated by the levels of

191 ethylene present without being consumed. In addition to the enzyme activation, an enzyme

192 turnover was assumed with the active enzyme being inactivated into its precursor again:

$$
E n z \stackrel{k_{i}}{\longrightarrow} E n z_{\text {pre }}
$$

194 with $k_{i}\left(\mathrm{~d}^{-1}\right)$ being the rate constant for the inactivation of the active enzyme. The dynamic

195 equilibrium between activation, both autocatalytic and through ethylene, and inactivation of 196 the model enzyme Enz allows different equilibrium amounts of Enz depending on the dynamic 197 temperature and ethylene levels. The model enzyme Enz is not a priori linked to any particular 198 single enzyme but reflects a whole complex of actual enzymes.

199 The outlined mechanism (Eqs. 2-5) was formulated as a set of differential equations describing 200 the changes over time.

201

$\frac{d[E n z]}{d t}=k_{a}\left[E n z_{p r e}\right][E n z]+k_{e}\left[E n z_{p r e}\right]\left[C_{2} H_{4}\right]-k_{i}[E n z]$

$$
\frac{d\left[E n z_{p r e}\right]}{d t}=-\frac{d[E n z]}{d t}
$$


$203 \quad \frac{d[C W]}{d t}=-k_{p}[E n z][C W]$

204 Each of the rate constants $\left(k_{p}, k_{a}, k_{e}\right.$ and $k_{i}$ ) was assumed to depend on temperature (T, in $\mathrm{K}$ ) 205 according to Arrhenius' Law:

$206 \quad k=k_{r e f} e^{\frac{E_{a}}{R}\left(\frac{1}{T_{r e f}}-\frac{1}{T}\right)}$

207 with $k_{\text {ref }}\left(\mathrm{d}^{-1}\right)$ being the value for $k$ at an arbitrary chosen reference temperature, $T_{\text {ref }}$ (in our 208 case $278.15 \mathrm{~K}), E a\left(\mathrm{~J} \mathrm{~mol}^{-1}\right)$ being the energy of activation and $R$ the universal gas constant $209 \quad\left(8.314 \mathrm{~J} \mathrm{~mol}^{-1} \mathrm{~K}^{-1}\right)$.

210

\subsection{Output relation}

211 The model assumes a complete breakdown of $C W$. However, as there will always be some

212 firmness left, a basic firmness level $\left(F_{f i x}\right)$ was introduced indicating the final asymptotic

213 firmness level to which kiwifruit would soften. Assuming the change in firmness to be one-to-

214 one related to the change in $C W$ this results in the final expression for firmness.

$215 \quad F(t)=C W(t)+F_{f i x}$

\subsection{Batch-dependent parameters}

217 The rate constants were assumed a property of the enzyme system involved. As it can be safely 218 assumed that the same enzyme system is involved in all kiwifruit, the rate constants and their 219 energies of activation can be assumed identical for all batches studied.

220 To account for differences between batches, each batch was allowed to start from its own initial 221 measured firmness $\left(F_{0}\right)$. As different batches vary in their maturity at harvest, the initial amount of active enzyme ( $E n z_{0}$, in arbitrary units) was allowed to vary between batches, with

223 the total amount of enzyme fixed at an arbitrary value of 100 resulting in: 
225 Fruit with high initial levels of Enzo are expected to soften faster than fruit with low initial 226 levels of $E n z_{0}$.

227 The model enzyme, $[E n z]$, comprises the whole complex enzyme system responsible for cell wall degradation in kiwifruit and as such is a gross simplification. However, the current data on fruit softening only allows for such a phenomenological type of model. For a biochemically 'correct' model, much more detailed experimental data is required. As such, this model positions itself somewhere in between a complete statistical black box model and the real life situation. The resulting model is technically capable of describing the known effects of time, temperature and ethylene on the softening of kiwifruit (Fig. 1).

The predictive power of the model lies on the ability to a priori determine the value of $E n z_{0}$.

The detailed characterisation of maturity explained in section 2.2.2 was used to investigate the relationship between the average maturity of a batch of kiwifruit and the batch specific model parameter $E n z_{0}$ driving fruit softening.

\subsection{Model calibration}

239 The current model uses time, temperature and exogenous ethylene, as input data, to predict

240 softening of kiwifruit. Firmness data measured as a compression force and obtained during storage for different time, under different temperature and ethylene, were used to calibrate the model. The developed model was implemented in its ordinary differential equation (ODE) form and model parameters were estimated using OptiPa (Hertog et al., 2007), a dedicated

244 optimisation tool which was developed using Matlab (The MathWorks, Inc., Natick, MA, 245 USA). In this programme a variable-step continuous solver, ODE45, was selected. By implementing the model as ODEs that are numerically solved for small time steps the model 
247 can solve at non-constant conditions for both temperature and ethylene. While analysing the

248 experimental data the conditions (temperature and ethylene levels) during the transition phase

249 were approximated assuming a one day linear transition of the conditions of the initial four

250 weeks storage period to the conditions of the final six weeks shelf life period.

251 The least square optimisation was carried out in OptiPa using the MATLAB least square non-

252 linear optimisation routine in combination with the Levenberg-Marquardt method.

253 4. Results and discussion

\subsection{Non-destructive versus destructive firmness measurement}

To investigate the relationship between the non-destructive and destructive technique, an asymmetric sigmoid function fitted to the data of the non-invasive compression firmness and penetrometer measurements could explain $96 \%$ of the observed variation (Fig. 2). This function could be used to transform non-destructive compression forces into standard destructive penetrometer values and vice versa. Similar non-linear relationships between nondestructive compression force and penetrometer measurements of kiwifruit firmness were reported by $\mathrm{Li}$ et al. (2016). By using mathematical modelling, Hertog et al. (2004a) demonstrated that softening measured by non-invasive techniques have components driven by both cell wall breakdown and water vapour pressure deficit. The shoulder of the curve at high firmness might have been caused by water loss from the fruit reducing the compression force, without much effect on the destructive firmness measure.

\subsection{Kiwifruit softening}

267 The experimental results on the softening of "Kiwistart" fruit from grower 1 at the different 268 storage temperatures, ethylene levels and shelf life temperatures applied are shown in Fig. 3 269 (For the results of all 14 grower lines, see Supplementary Table S1). A malfunction of one of 
the cold rooms meant that fruit being tested at a shelf life at $0{ }^{\circ} \mathrm{C}$ were lost prematurely because of freezing damage. The limited storage data on these fruit were still included in the analysis.

272 As expected, storage temperature had a pronounced effect on the rate of softening (Fig. 3).

273 Fruit softened faster with increasing temperature. Even storage at $2{ }^{\circ} \mathrm{C}$ sped up the softening 274 process compared to $0{ }^{\circ} \mathrm{C}$ storage. With increasing temperature, the initial slow softening phase 275 shortens and the fruit almost immediately start to soften rapidly.

276 At $0{ }^{\circ} \mathrm{C}$, ethylene levels as low as $0.1 \mu \mathrm{L} \mathrm{L}^{-1}$ clearly enhanced the softening of "Kiwistart" 277 fruit. The response of the fruit to increasing levels of exogenous ethylene was fully saturated 278 at $10 \mu \mathrm{L} \mathrm{L}^{-1}$ ethylene, as $200 \mu \mathrm{L} \mathrm{L}^{-1}$ caused no further accelerated softening (Fig. 3D cf. Fig. 279 3C). This observation was in agreement with Jeffery and Banks (1996). As with temperature, 280 increasing levels of ethylene shortened the initial slow softening phase and forced the fruit into 281 the rapid exponential softening phase.

282 Fruit from all growers softened to about the same final firmness level and no differences between the 14 grower lines in terms of their responses to the applied conditions were apparent (Supplementary Table S1).

\subsection{Model results}

As the rate constants were assumed properties of the involved enzyme system, all rate constants and their energies of activation were estimated in common for all growers. As our results indicated that fruit from all growers softened to about the same final level, the value for $F_{f i x}$ was also estimated in common. To allow for different softening rates between lines related to different maturity levels, the initial amount of active enzyme ( $\left.E n z_{0}\right)$ was allowed to differ between the 14 grower lines studied. The model parameter estimates are shown in Table 2 .

The developed model, fitted on the measured data using least square non-linear regression, accounted for $97 \%$ of the observed variation for all 14 grower lines. The residuals were evenly 
294 scattered around the line $\mathrm{X}=\mathrm{Y}$ indicating a good agreement between model and measurements

295 (Fig. 4). The model tended to underestimate some of the higher firmness levels related to the transition zone between the initial relative slow softening phase and the main rapid softening

297 phase (Fig. 3B). There were no systematic deviations related to grower, storage temperature,

298 shelf life temperature or applied ethylene level. The model was able to accurately account for

299 the observed responses of "Kiwistart" fruit to time, temperature and exogenous applied 300 ethylene levels.

301 The 14 grower lines show different levels of $E n z_{0}$ (Table 2). The high value of $E n z_{0}$ for grower one resembled the relative fast softening of fruit from this grower as compared to fruit from the other growers (Supplementary Table S1). With all rate constants being in common for all growers and the initial firmness measured at harvest, the model parameter $E n z_{0}$ is the determining parameter to identify how fast a specific batch of fruit will soften during storage.

\section{Model validation}

307 To test the generic value of the developed model, two independent sets of data were used to validate the model. In both cases, the kinetic model parameter values were set at the previously estimated values based on the experimental data described above.

\subsection{Batch-to-batch variation}

311 A set of data measuring the softening of 70 different grower lines of main harvest kiwifruit was

312 used to investigate the extent of batch dependency of the model parameter $E n z_{0}$. Firmness was 313 measured destructively at four-weekly intervals over 24 weeks of air storage at $0{ }^{\circ} \mathrm{C}$. The 314 ethylene levels during storage were assumed negligible. The relationship from Fig. 2 was used

315 to convert the model output from compression force into standard penetrometer values. The 316 final firmness level for this main harvest fruit was generally higher than found for the 
317 "Kiwistart" fruit. To account for this difference, $F_{f i x}$ was set at $11.8 \mathrm{~N}$, the lowest final firmness

318 level recorded between the 70 grower lines after 24 weeks of storage.

319 If the developed model is generic, it should be possible to explain the dynamics of fruit 320 softening by their measured initial firmness $\left(F_{0}\right)$ and by estimating the only remaining model 321 parameter $E n z_{0}$. The model explained in average $99 \%$ of the observed variation for each of 322 the grower lines involved in the validation trial, reflecting the generic value of the model in its 323 ability to describe softening behaviour of kiwifruit originating from a wide range of growing 324 conditions and maturity levels.

325 The estimated values of $E n z_{0}$ covered the entire scale, ranging from 0 to 100 (Fig. 5).

326 Generally, the estimates for $E n z_{0}$ were higher than those obtained for the "Kiwistart" fruit 327 reflecting the fact that "Kiwistart" fruit is harvested more immature, earlier in the season. It 328 would be interesting to see how these values relate to maturity of the fruit as defined by atharvest attributes.

330 To this end, the at-harvest attributes measured for the subset of 27 grower lines was examined.

331 Using these data, a multiple linear regression was performed to see whether the measured atharvest attributes could be linked to the estimated values for $E n z_{0}$. Using all the nine available attributes, $69 \%$ of the observed variation in $E n z_{0}$ could be explained (Table S2). However, the

334 five most relevant attributes were initial firmness, $\mathrm{N}, \mathrm{K}, \mathrm{Mg}$ and reducing sugars, together 335 explaining $62 \%$ of the observed variation in $E n z_{0}$ (Fig. 6). The inclusion of minerals is not 336 completely unexpected as it has been shown that a number of mineral nutrients are related to 337 kiwifruit storability (Benge et al., 2000a; Feng et al., 2006; Prasad and Spiers, 1992). In addition reducing sugars, strongly correlated to SSC, are known to increase during kiwifruit ripening, as a result of starch breakdown (Park et al., 2015). However, one should be aware 
340 that in the case of multiple linear regression with highly correlated variables the regression

341 coefficients do not necessarily reflect causal relationships, but merely represent numerical

342 relations and therefore should not be over interpreted. The main practical outcome of this

343 validation is that the at harvest attributes could be used to guestimate the value of the batch

344 specific model parameter Enz $z_{0}$ allowing for batch specific prediction of the postharvest

345 softening of kiwifruit. Also other indicators of fruit's physiological state, not routinely used to

346 estimate commercial maturity of kiwifruit, such as ethylene production, respiration rates, and

347 the activities of certain cell wall hydrolases, could be useful in predicting $E n z_{0}$.

\subsection{Ethylene treatment}

349 The second independent set of data was obtained from a PhD thesis from Parmentier (1998) on the shipment of "Kiwistart" fruit. In 1996, Parmentier recorded fruit firmness, temperature and ethylene levels during the shipping of "Kiwistart" fruit from Tauranga, New Zealand, to Zeebrugge, Belgium. The recorded temperature (Fig. 7A) and ethylene (Fig. 7B) profiles were used as dynamic inputs for the model, together with the measured initial firmness of the fruit.

354 The parameter $E n z_{0}$ was set to a value of 7.8 (the average value encountered for the 14

"Kiwistart" growers in the current study). The final firmness $\left(F_{f i x}\right)$ was set to a value of 13.1

$\mathrm{N}$, based on a forced ripening experiment Parmentier (1998) performed on her fruit. Although this value seemed to be high, this value agreed to the final firmness value fruit softened to during the shipping trial (Fig. 7C). Again, the relationship from Fig. 2 was used to convert the model output from compression force into standard penetrometer values.

360 The close agreement between observed and predicted softening (Fig 7C) provides confidence

361 that the model may be applicable to dynamic temperature and ethylene scenarios as commonly

362 observed during the shipping of kiwifruit. 


\section{Conclusions}

364 The developed model on softening of kiwifruit accurately accounted for the observed responses

365 of "Kiwistart" fruit to time, temperature and exogenous applied ethylene levels. By using this

366 model, one would be able to optimise ripening protocols for "Kiwistart" fruit based on exposure

367 to temperatures and ethylene concentration including its impact on the fruit's remaining shelf

368 life.

369 As all rate constants appeared to be in common for the studied growers, initial firmness and

370 the model parameter $E n z_{0}$ are the only determining parameters to identify how fast a specific

371 batch of fruit softens under certain storage conditions.

372 The model's generic character was displayed by its ability to describe independent softening

373 data on kiwifruit originating from a wide range of growing conditions and maturity levels. The

374 model has also proven its ability to describe dynamic temperature and ethylene conditions as

375 commonly observed during the shipping of kiwifruit. Given this generic value of the model, it

376 could be used as a predictive tool to manage specific batches of fruit, assuming the batch

377 specific model parameter Enzo can be determined at harvest.

378 7. Acknowledgements

379 This work was commercially funded by ZESPRI Innovation Ltd, Tauranga, New Zealand. 


\section{References}

Benge, J.R., Banks, N.H., Tillman, R., De Silva, H.N., 2000a. Pairwise compsrison of the storage potential of kiwi fruit from organic and conventional production systems. N. Z. J. Crop Hortic. Sci. 28, 147-152. doi:10.1080/01140671.2000.9514134

Benge, J.R., De Silva, H.N., Banks, N.H., Jeffery, P.B., 2000b. Empirical modelling of postharvest changes in the firmness of kiwifruit. Postharvest Biol. Technol. 19, 211-220.

Bonghi, C., Pagni, S., Vidrih, R., Ramina, A., Tonutti, P., 1996. Cell wall hydrolases and amylase in kiwifruit softening. Postharvest Biol. Technol. 9, 19-29. doi:10.1016/09255214(96)00025-7

Burdon, J., Pidakala, P., Martin, P., McAtee, P.A., Boldingh, H.L., Hall, A., Schaffer, R.J., 2014. Postharvest performance of the yellow-fleshed "Hort16A" kiwifruit in relation to fruit maturation. Postharvest Biol. Technol. 92, 98-106. doi:10.1016/j.postharvbio.2014.01.004

Feng, J., Maguire, K.M., MacKay, B.R., 2006. Discriminating batches of “Hayward” kiwifruit for storage potential. Postharvest Biol. Technol. 41, 128-134. doi:10.1016/j.postharvbio.2006.03.010

Gwanpua, S.G., Verlinden, B.E., Hertog, M.L.A.T.M., Bulens, I., Van de Poel, B., Van Impe, J., Nicolaï, B.M., Geeraerd, A.H., 2012. Kinetic modeling of firmness breakdown in "Braeburn" apples stored under different controlled atmosphere conditions. Postharvest Biol. Technol. 67, 68-74. doi:10.1016/j.postharvbio.2011.12.010

Gwanpua, S.G., Verlinden, B.E., Hertog, M.L.A.T.M., Van Impe, J., Nicolai, B.M., Geeraerd, A.H., 2013. Towards flexible management of postharvest variation in fruit firmness of three apple cultivars. Postharvest Biol. Technol. 85, 18-29. doi:10.1016/j.postharvbio.2013.04.015

Hertog, M.L.A.T.M., Ben-Arie, R., Róth, E., Nicolaï, B.M., 2004a. Humidity and temperature 
effects on invasive and non-invasive firmness measures. Postharvest Biol. Technol. 33, 79-91. doi:http://dx.doi.org/10.1016/j.postharvbio.2004.01.005

408

409

410

411

412

413

414

415

416

417

418

419

420

421

422

423

424

425

426

427

428

429

430

Hertog, M.L.A.T.M., Nicholson, S.E., Banks, N.H., 2001. The effect of modified atmospheres on the rate of firmness change in "Braeburn" apples. Postharvest Biol. Technol. 23, 175184. doi:10.1016/S0925-5214(01)00126-0

Hertog, M.L.A.T.M., Nicholson, S.E., Jeffery, P.B., 2004. The effect of modified atmospheres on the rate of firmness change of "Hayward" kiwifruit. Postharvest Biol. Technol. 31, 251-261. doi:10.1016/j.postharvbio.2003.09.005

Hertog, M.L.A.T.M., Nicholson, S.E., Whitmore, K., 2003. The effect of modified atmospheres on the rate of quality change in "Hass" avocado. Postharvest Biol. Technol. 29, 41-53. doi:10.1016/S0925-5214(02)00211-9

Hertog, M.L.A.T.M., Verlinden, B.E., Lammertyn, J., Nicolaï, B.M., 2007. OptiPa, an essential primer to develop models in the postharvest area. Comput. Electron. Agric. 57, 99-106. doi:10.1016/j.compag.2007.02.001

Jabbar, A., 2014. Accelerated fruit libraries to predict storage potential of "Hayward" kiwifruit grower lines : a thesis presented in partial fulfilment of the requirements for the degree of Doctor of Philosophy in Food Technology at Massey University, New Zealand.

Jabbar, A., East, A.R., 2016. Quantifying the ethylene induced softening and low temperature breakdown of "Hayward" kiwifruit in storage. Postharvest Biol. Technol. 113, 87-94. doi:10.1016/j.postharvbio.2015.11.002

Jabbar, A., East, A.R., Jones, G., Tanner, D.J., Heyes, J.A., 2014. Modelling batch variability in softening of "Hayward" kiwifruit from at-harvest maturity measures. Postharvest Biol. Technol. 90, 7-14. doi:10.1016/j.postharvbio.2013.11.008

Jeffery, P.B., Banks, N.H., 1996. Effects of ethylene on kiwifruit softening in coolstorage. NZ Kiwifruit J. 9-10. 
Lallu, N., Searle, A.N., Macrae, E.A., 1989. An investigation of ripening and handling strategies for early season kiwifruit (Actinidia deliciosa cv Hayward). J. Sci. Food Agric. 47, 387-400. doi:10.1002/jsfa.2740470402

Li, H., Pidakala, P., Billing, D., Burdon, J., 2016. Kiwifruit firmness: Measurement by penetrometer and non-destructive devices. Postharvest Biol. Technol. 120, 127-137. doi:10.1016/j.postharvbio.2016.06.007

MacRae, E.A., Redgwell, R.J., Wegrzyn, T.F., 1990. The whens and hows of fruit softening. NZ Kiwifruit 15-17.

Ochoa-Ascencio, S., Hertog, M.L.A.T.M., Nicolaï, B.M., 2009. Modelling the transient effect of 1-MCP on "Hass" avocado softening: A Mexican comparative study. Postharvest Biol. Technol. 51, 62-72. doi:10.1016/j.postharvbio.2008.06.002

Park, Y.S., Im, M.H., Gorinstein, S., 2015. Shelf life extension and antioxidant activity of "Hayward" kiwi fruit as a result of prestorage conditioning and 1-methylcyclopropene treatment. J. Food Sci. Technol. 52, 2711-2720. doi:10.1007/s13197-014-1300-3

Parmentier, V., 1998. Handling of New Zealand Kiwifruit in Europe. Katholieke Universiteit Leuven, Belgium.

Pranamornkith, T., East, A., Heyes, J., 2012. Influence of exogenous ethylene during refrigerated storage on storability and quality of Actinidia chinensis (cv. Hort16A). Postharvest Biol. Technol. 64, 1-8. doi:10.1016/j.postharvbio.2011.09.011

Prasad, M., Spiers, T.M., 1992. The effect of nutrition on the storage quality of kiwifruit (a review). Acta Hortic. 297, 579-586. doi:10.17660/ActaHortic.1992.297.76

Redgwell, R.J., Melton, L.D., Brasch, D.J., 1992. Cell Wall Dissolution in Ripening Kiwifruit (Actinidia deliciosa) : Solubilization of the Pectic Polymers. Plant Physiol. 98, 71-81.

Ritenour, M.A., Crisosto, C.H., Garner, D.T., Cheng, G.W., Zoffoli, J.P., 1999. Temperature, length of cold storage and maturity influence the ripening rate of ethylene-preconditioned 
457 Schröder, R., Atkinson, R.G., 2006. Kiwifruit cell walls: Towards an understanding of softening? New Zeal. J. For. Sci. 36, 112-129.

Tijskens, L.M.M., Rodis, P.S., Hertog, M.L.A.T.M., Kalantzi, U., van Dijk, C., 1998. Kinetics of polygalacturonase activity and firmness of peaches during storage. J. Food Eng. 35,

Van Dijk, C., Boeriu, C., Peter, F., Stolle-Smits, T., Tijskens, L.M.M., 2006. The firmness of 463 stored tomatoes (cv. Tradiro). 1. Kinetic and near infrared models to describe firmness and moisture loss. J. Food Eng. 77, 575-584. doi:10.1016/j.jfoodeng.2005.07.029

465

\section{Tables}

466

Table 1: Shelf life temperatures $\left(\right.$ in ${ }^{\circ} \mathrm{C}$ ) applied to the different grower batches after storage at 467 the temperaturexethylene level combinations indicated. $\left(T_{\text {stor }}\right.$ storage temperature in $\left.{ }^{\circ} \mathrm{C}\right) ; \mathrm{C}_{2} \mathrm{H}_{4}$ : 468 exogenous applied ethylene level in $\mu \mathrm{L} \mathrm{L}^{-1}$ )

\begin{tabular}{|c|c|c|c|c|}
\hline \multicolumn{5}{|l|}{ Grower 1} \\
\hline $\mathrm{C}_{2} \mathrm{H}_{4} T_{\text {stor }}$ & 0 & 2 & 5 & 10 \\
\hline 0 & 20 & 0 & 5 & 10 \\
\hline 0.1 & 0 & 5 & 10 & 20 \\
\hline 10 & 10 & 20 & 0 & 5 \\
\hline 200 & 5 & 10 & 20 & 0 \\
\hline
\end{tabular}

Grower 3 2000 season

\begin{tabular}{|l|l|l|l|l|}
\hline \multicolumn{1}{r|}{$T_{\text {stor }}$} & 0 & 2 & 5 & 10 \\
\hline $\mathrm{C}_{2} \mathrm{H}_{4}$ & & & & \\
\hline 0 & 5 & 10 & 20 & 0 \\
\hline 0.1 & 10 & 20 & 0 & 5 \\
\hline 10 & 0 & 5 & 10 & 20 \\
\hline 200 & 20 & 0 & 5 & 10 \\
\hline
\end{tabular}

\begin{tabular}{|c|c|c|c|c|}
\hline \multicolumn{5}{|l|}{ Grower 2} \\
\hline$\overbrace{\mathrm{C}_{2} \mathrm{H}_{4}} T_{\text {stor }}$ & 0 & 2 & 5 & 10 \\
\hline 0 & 0 & 5 & 10 & 20 \\
\hline 0.1 & 20 & 0 & 5 & 10 \\
\hline 10 & 5 & 10 & 20 & 0 \\
\hline 200 & 10 & 20 & 0 & 5 \\
\hline
\end{tabular}

\section{Grower 4}

\begin{tabular}{|c|c|c|c|c|}
\hline $\mathrm{C}_{2} \mathrm{H}_{4} T_{\text {stor }}$ & 0 & 2 & 5 & 10 \\
\hline 0 & 10 & 20 & 0 & 5 \\
\hline 0.1 & 5 & 10 & 20 & 0 \\
\hline 10 & 20 & 0 & 5 & 10 \\
\hline 200 & 0 & 5 & 10 & 20 \\
\hline
\end{tabular}

\section{1 season}

Growers 1-4
\begin{tabular}{|l|l|l|}
\hline$T_{\text {stor }}$ & 0 & 2 \\
$\mathrm{C}_{2} \mathrm{H}_{4}$ & & \\
\hline 0 & 20 & 0 \\
\hline 2 & 0 & 10 \\
\hline 100 & 10 & 20 \\
\hline
\end{tabular}

\begin{tabular}{|c|c|c|}
\hline \multicolumn{3}{|c|}{ growers 5-7 } \\
\hline$T_{\text {stor }}$ & 0 & 2 \\
\hline 0 & 10 & 20 \\
\hline 2 & 20 & 0 \\
\hline 100 & 0 & 10 \\
\hline
\end{tabular}

Grower 8-10
\begin{tabular}{|l|l|l|}
\hline \multicolumn{1}{|l|}{$T_{\text {stor }}$} & 0 & 2 \\
$\mathrm{C}_{2} \mathrm{H}_{4}$ & & \\
\hline 0 & 0 & 10 \\
\hline 2 & 10 & 20 \\
\hline 100 & 20 & 0 \\
\hline
\end{tabular}


471 Table 2: Model parameter estimates, together with the approximated standard error (S.E).

\begin{tabular}{lll}
\hline \multicolumn{2}{c}{ a Parameter } & Estimate (S.E) \\
\hline & Grower 1 & $27(11)$ \\
& Grower 2 & $2.7(1.9)$ \\
& Grower 3 & $1.9(1.2)$ \\
& Grower 4 & $5.3(2.5)$ \\
& Grower 5 & $5.8(3.2)$ \\
& Grower 6 & $7.8(4.1)$ \\
$E n z_{0}$ & Grower 7 & $7.4(3.4)$ \\
& Grower 8 & $6.8(3.9)$ \\
& Grower 9 & $6.0(3.4)$ \\
& Grower 10 & $7.9(4.7)$ \\
& Grower 11 & $6.4(3.4)$ \\
& Grower 12 & $9.5(4.2)$ \\
& Grower 13 & $8.4(3.6)$ \\
& Grower 14 & $7.1(3.2)$ \\
\hline$k_{p, r e f}$ & & $0.00092(0.00003)$ \\
$k_{a, r e f}$ & & $0.0079(0.0015)$ \\
$k_{e, r e f}$ & & $1.1(0.3)$ \\
$k_{i, r e f}$ & & $0.45(0.09)$ \\
$E_{a, p}$ & & $100000(3400)$ \\
$E_{a, a}$ & & $94000(5100)$ \\
$E_{a, e}$ & & 0 \\
$E_{a, i}$ & & $110000(4500)$ \\
$F_{f i x}$ & & $3.2(0.2)$ \\
\hline & &
\end{tabular}

$472{ }^{a} E n z_{0}$ is the initial level of active enzymes responsible for softening; $k_{p, r e f}, k_{a, r e f}, k_{e, r e f}$, are 473 the rate constants, at a reference temperature of $5^{\circ} \mathrm{C}$, for the enzymatic breakdown of cell wall, 474 activation of the enzymes responsible for softening, activation of enzymes by ethylene, and 475 inactivation of active enzymes, respectively; $E_{a, p}, E_{a, a}, E_{a, e}, E_{a, i}$ are the activation energies 476 for the enzymatic breakdown of cell wall, activation of the enzymes responsible for softening, 477 activation of enzymes by ethylene, and inactivation of active enzymes, respectively; $F_{f i x}$ is the 478 final compression force. $E_{a, e}$ was set to 0 to avoid over parametrisation of the model. 


\section{Figure Caption}

481 Fig. 1 General behaviour of the developed model (Eqs. 1-5) describing non-destructive

482 firmness measured as compression force as a function of time, temperature and exogenous 483 ethylene levels. The solid bottom plane represents softening at $1 \mu \mathrm{L} \mathrm{L}^{-1}$ ethylene while the top transparent plane represents softening at $0 \mu \mathrm{L} \mathrm{L}^{-1}$ ethylene.

Fig. 2 Non-destructive firmness measured as the maximum force at $1.5 \mathrm{~mm}$ compression of intact fruit as compared to standard destructive firmness measured as maximum force incurred during a $9 \mathrm{~mm}$ deep penetration of pared fruit tissue. The curve represents the asymmetric sigmoid fitted to the data.

Fig. 3 Softening of "Kiwistart" fruit from grower 1 at the different storage temperatures, ethylene levels and shelf life temperatures applied. Temperatures are indicated by the different

491 line/symbol colours (and types). Each of the graphs from A to D covers the result from one $\mathrm{C}_{2} \mathrm{H}_{4}$ treatment during storage, as indicated in the corner of each graph. The vertical lines at day 30 indicate the transition from storage phase to shelf life phase. The symbols represent the measured experimental values with the error bars indicating the standard deviation of these measurements based on 30 fruit measurements per point. The lines represent the fitted model from Eqs. 2-11, with model parameters reported in Table 2.

497 Fig. 4 Measured compression force (N) as compared to modelled compression force values for 498 all measurements taken on "Kiwistart" fruit from all 14 grower lines stored at the different 499 storage temperatures, ethylene levels and shelf life temperatures applied.

500 Fig. 5 Frequency distribution of Enzo estimated for the 70 grower lines measured during the main harvest validation trial. 
502 Fig. 6 Predicted Enz 0 based on a multiple linear regression on at-harvest parameters (initial 503 firmness, nitrogen, potassium, magnesium and reducing sugars) versus the estimated Enz $\mathrm{E}_{0}$ for 504 a subset of 27 grower lines.

505 Fig. 7 Shipment data from Parmentier (1998) monitoring temperature (A), applied ethylene 506 levels (B) and fruit firmness of "Kiwistart" fruit during and after shipping to Europe. The 507 symbols in $(\mathrm{C})$ represent the measured values while the line in $(\mathrm{C})$ represents the model 508 predictions based on the measured temperature and ethylene levels from (A) and (B). 


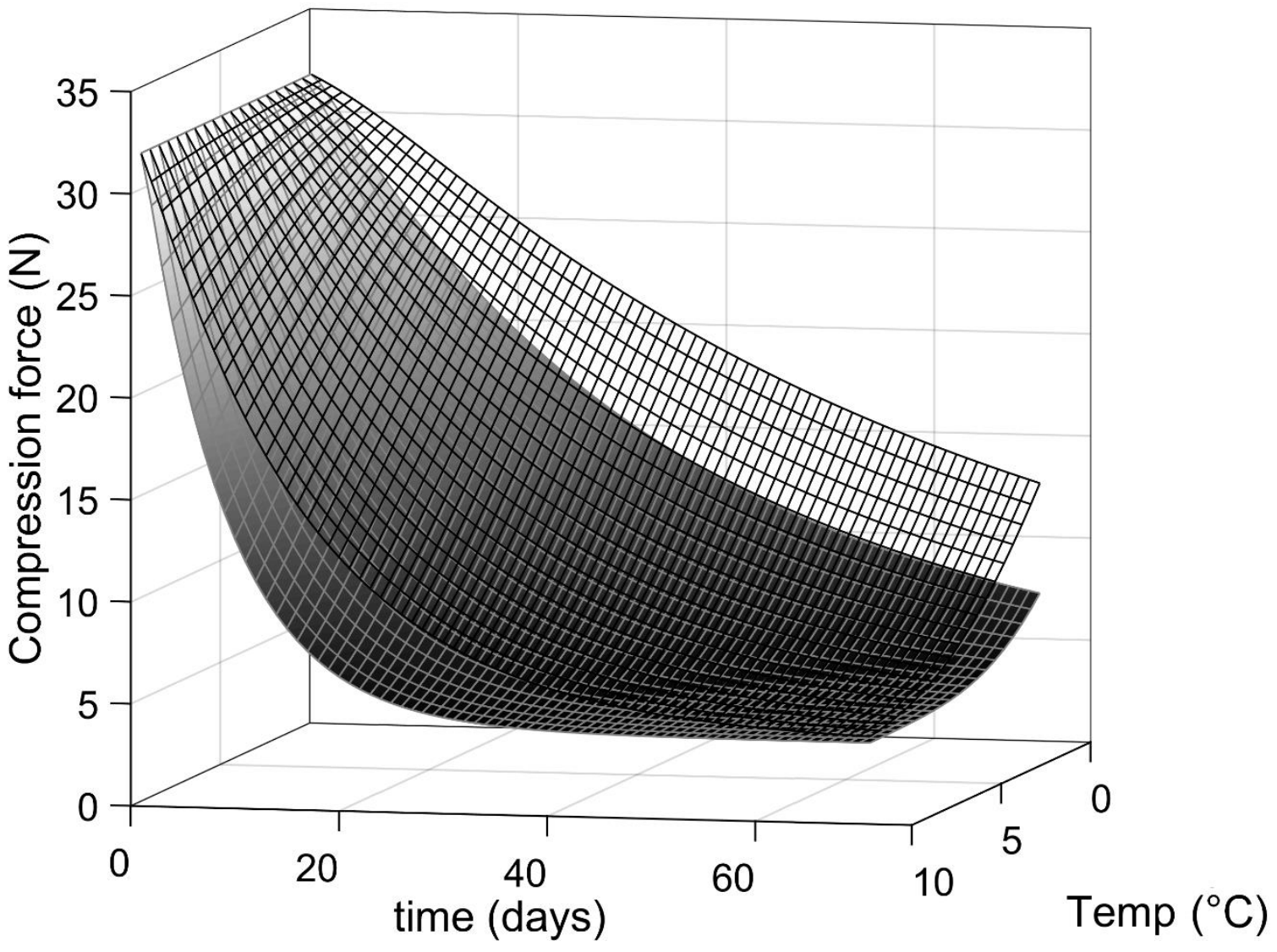

512 Figure 1. 


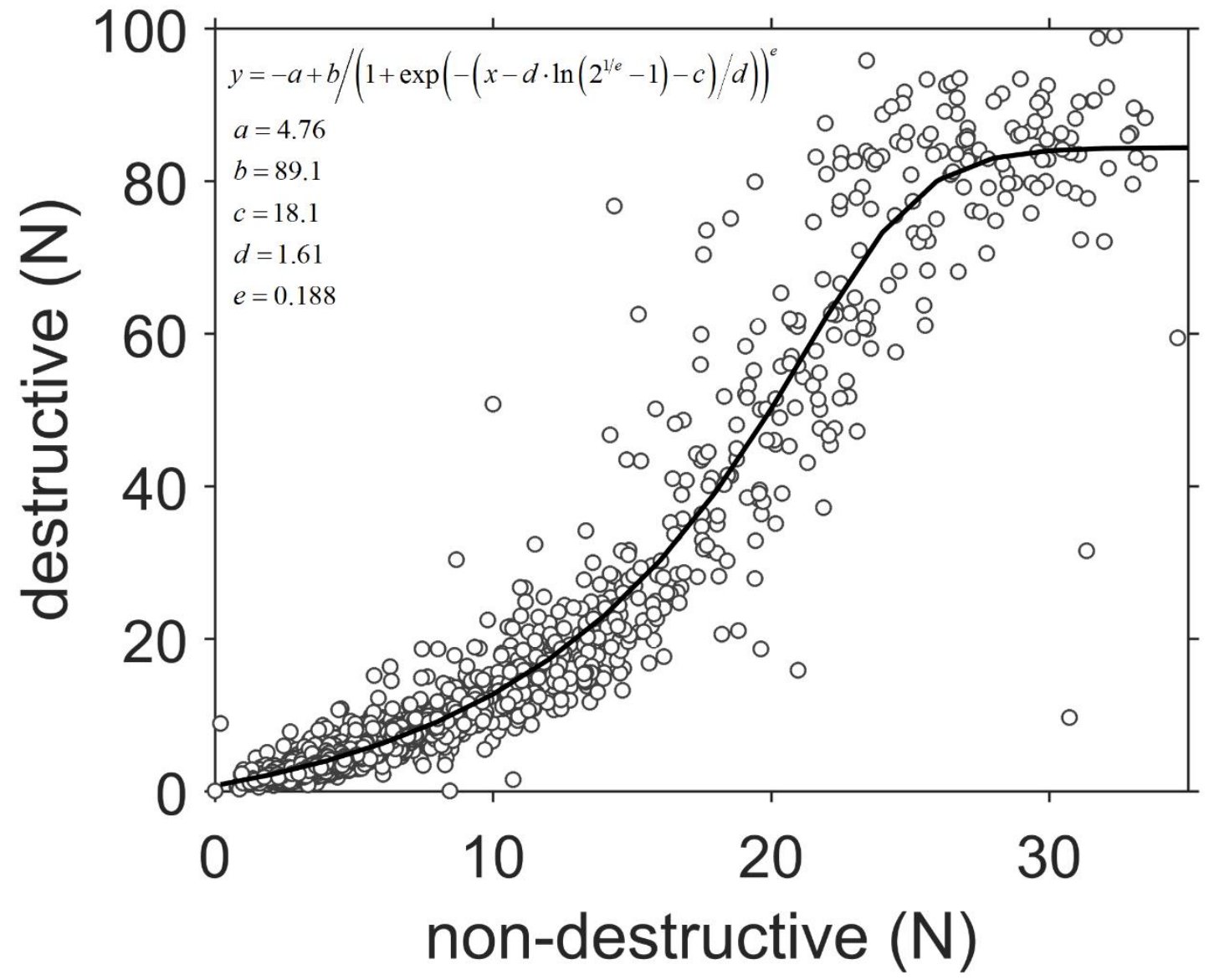

514 Figure 2. 

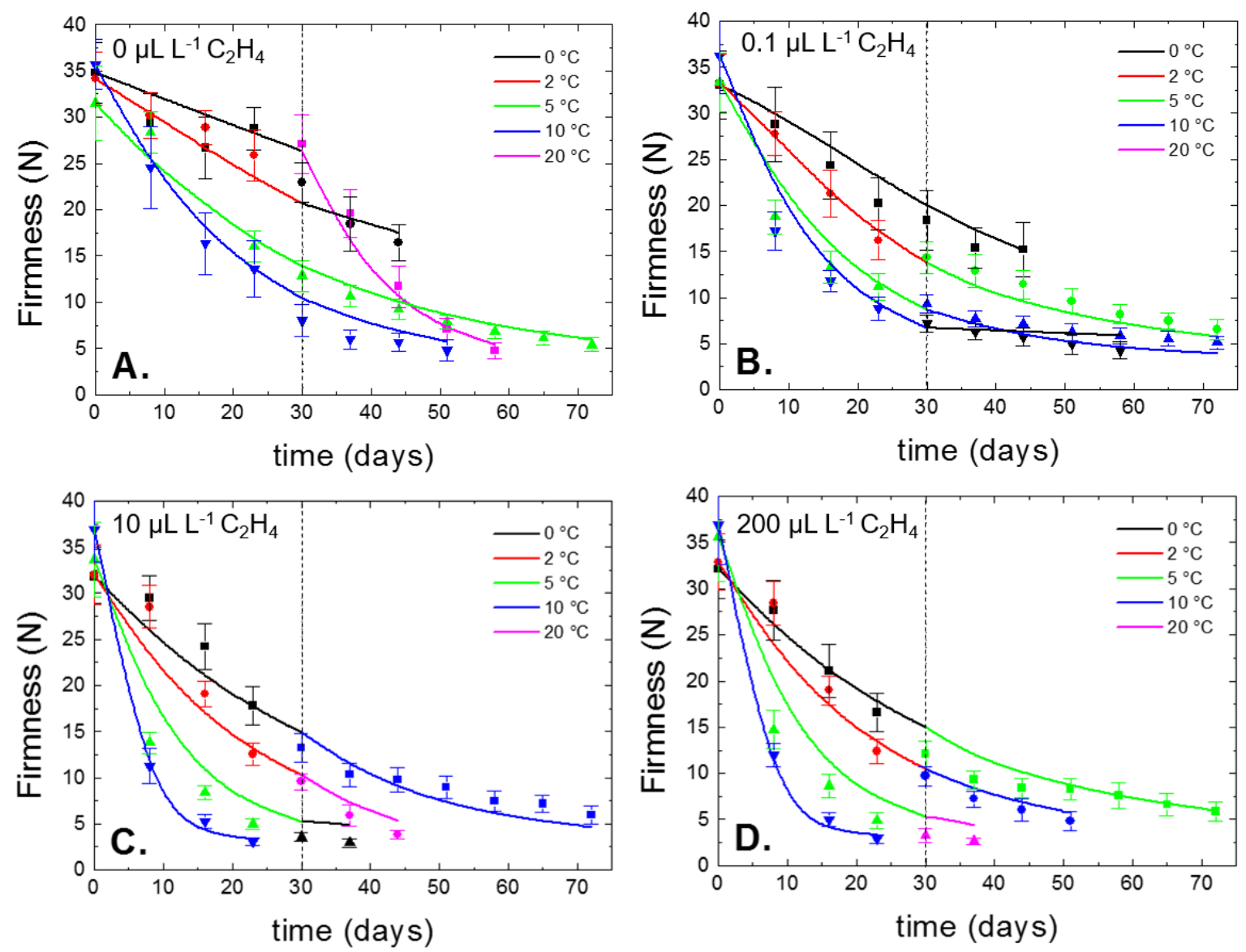

516 Figure 3. 


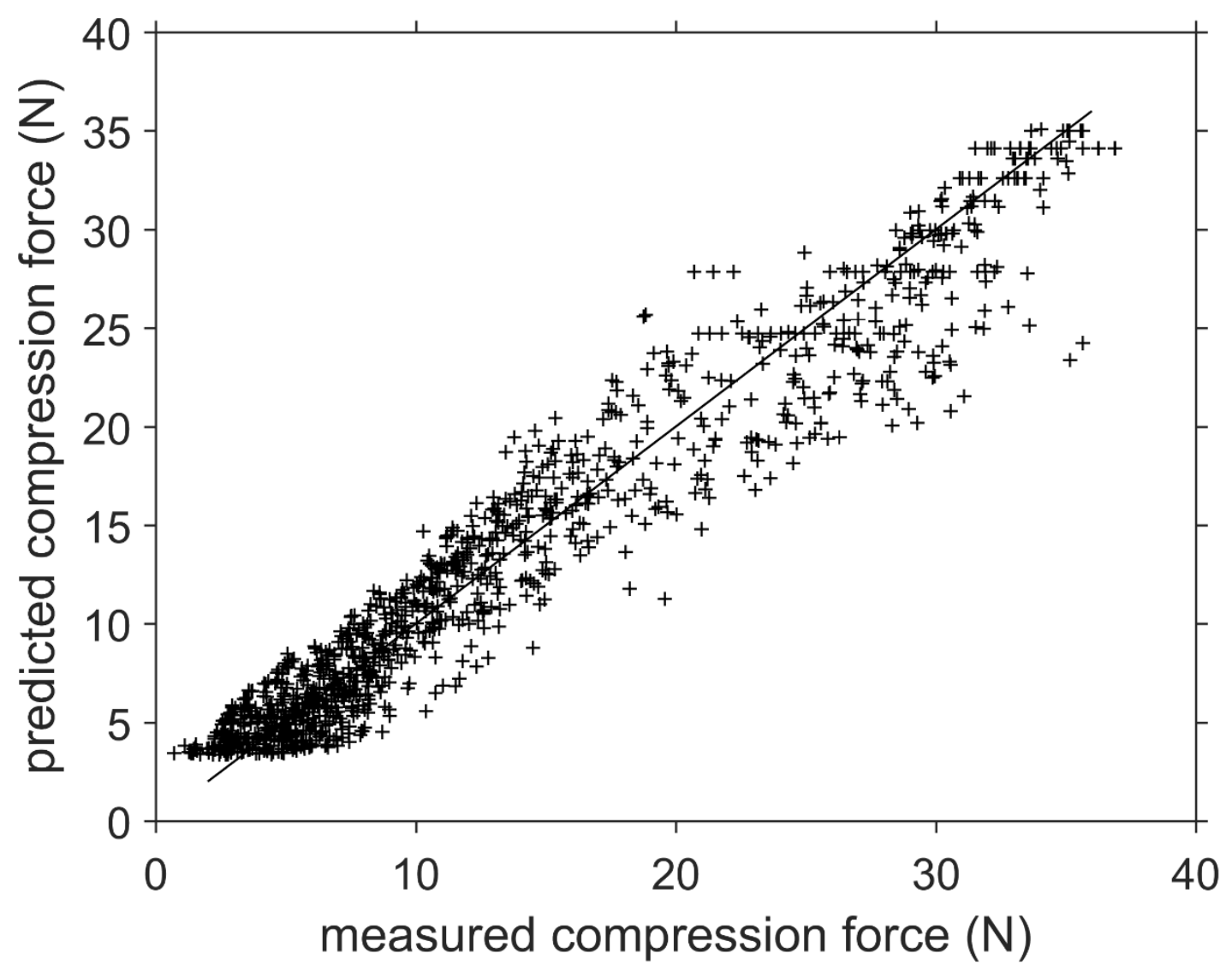

518 Figure 4.

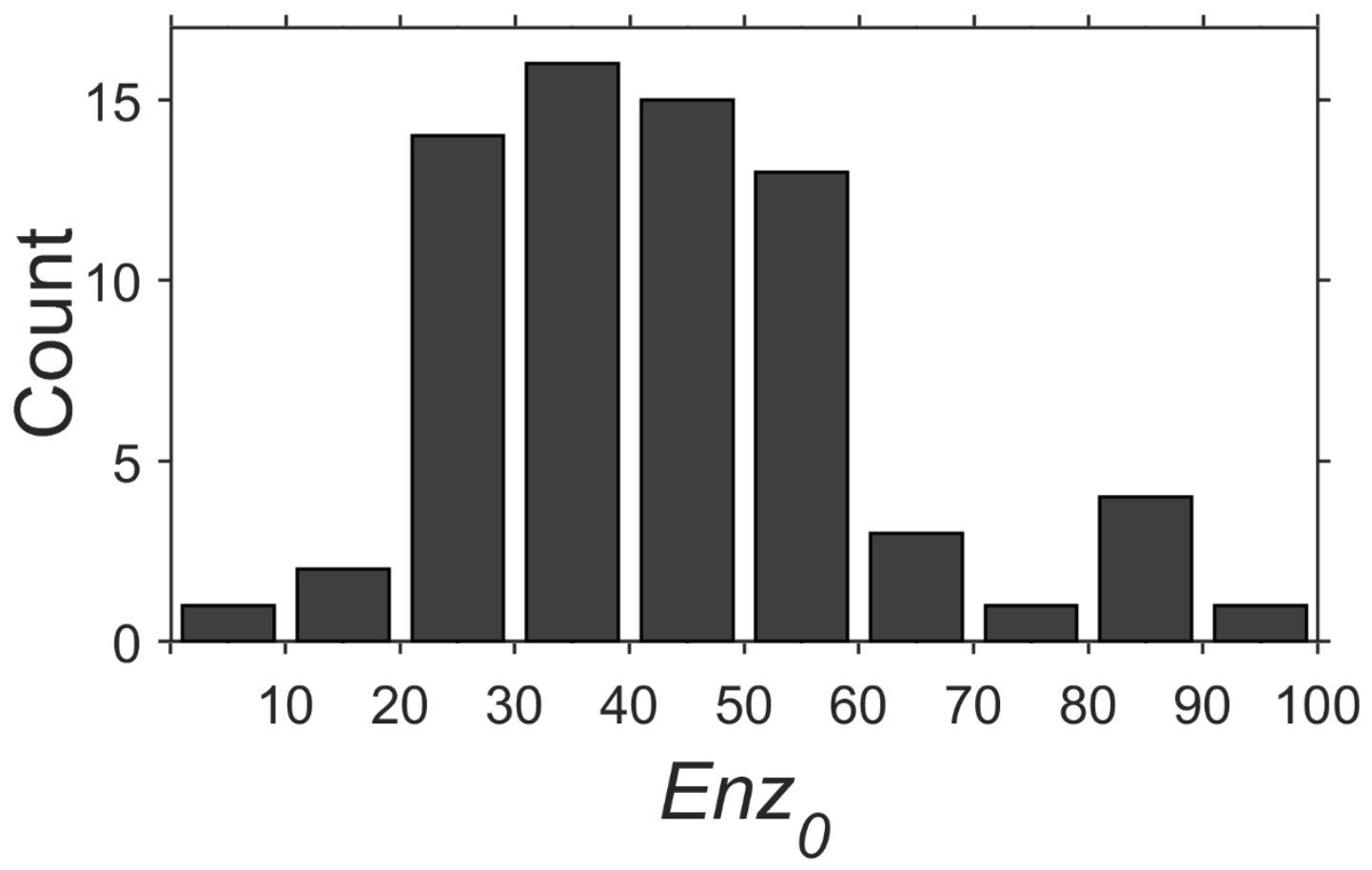

$520 \quad$ Figure 5. 


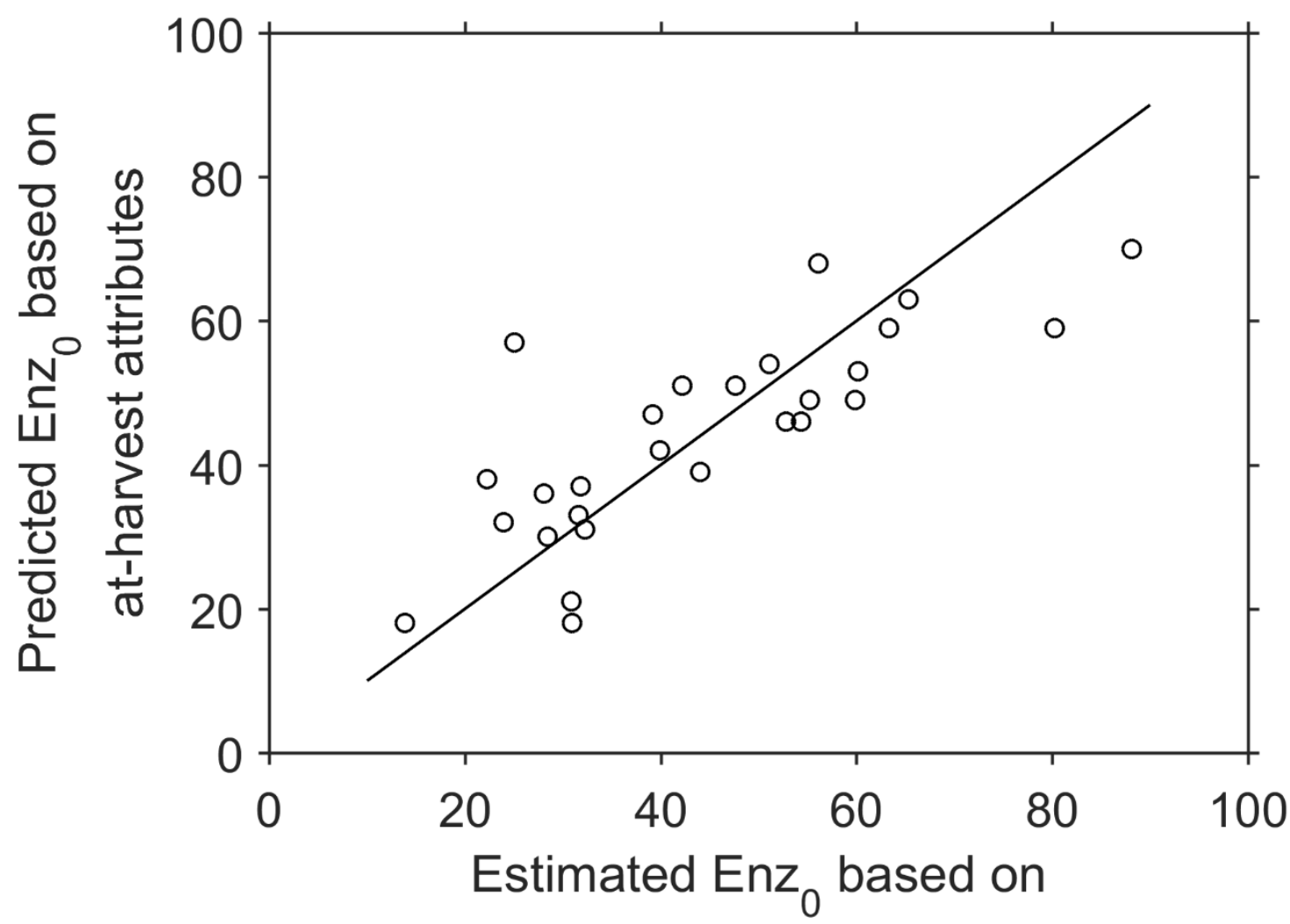

521 softening data

522 Figure 6. 


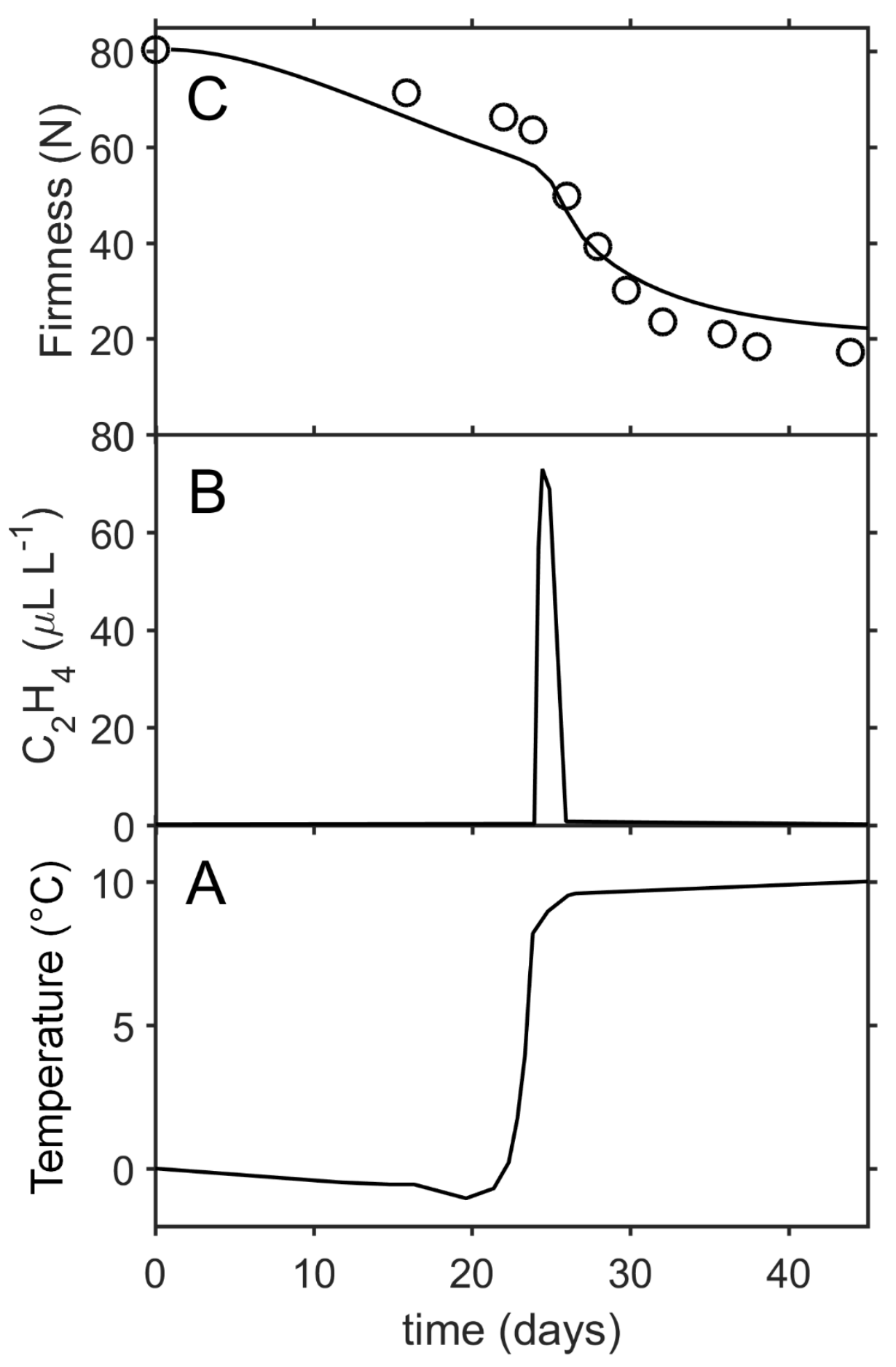

523

$524 \quad$ Figure 7. 